\title{
Peace Engineering: A Recipe of Proactive Engagement for the Betterment of Humanity
}

\section{Dr. Ashraf Ghaly P.E., Union College}

Ashraf Ghaly is Director of Engineering and Carl B. Jansen Professor of Engineering at Union College, Schenectady, NY. Published over 250 papers, technical notes, and reports. Supervised over 50 research studies. Registered PE in NYS. ASCE Fellow and Member of the Chi-Epsilon Civil Engineering Honor Society. 


\title{
Peace Engineering: A Recipe of Proactive Engagement for the Betterment of Humanity
}

\author{
Ashraf Ghaly, Ph.D., P.E., Professor \\ Engineering Department, Union College, Schenectady, NY 12308
}

\begin{abstract}
Throughout history, humans roamed the Earth in pursuit of food and water; minimum necessities for living. People had tendency to settle lands where means of survival and thriving existed. Scarcity of favorable land, coupled with population increase, intensified competition for resources and this, oftentimes, flared into conflicts. Violence and war were used to settle such conflicts, and this left behind nothing but misery and destruction. War did not only inflict damage on the defeated party but it was also costly to the triumphant one. Sadly, this scenario has repeated itself untold number of times throughout history and, more regrettably, it is still playing itself to this day in many regions around the world. With this in mind, engineers as well as non-engineers have a role to play to ameliorate living conditions for humans everywhere to reduce the possibility of war and conflict. The question humanity in general and engineers in particular are faced with is how to engineer peace and employ various skills to build a better future for all. The answer to this question starts with an attempt to combat the factors that ultimately lead to conflict. Peace engineering is a branch of study in which engineering and non-engineering students are trained to think critically across many disciplines to use technical solutions involving science and engineering, together with policy, to address societal ills resulting from natural disasters, man-made disasters, irresponsible and non-sustainable consumption of resources, pollution and contamination, and lack of opportunity. This program trains students to pursue practical solutions that proactively promote peace and reduce the potential for disputes in a world plagued with problems that require unconventional thinking to overcome. Students are exposed to innovative approaches toward addressing multidimensional problems in addition to gaining skill in economic, social, environmental, political, ethical, legal, cultural, and historical aspects associated with the effort of building enduring peace. This paper will detail the elements that constitute a peace engineering program. It will use real world examples to show how such a program could alter the way students look at finding solutions that make a difference in people's lives. The program's main objective is to inspire students to become agents to advance humanity toward an optimistic and a brighter tomorrow.
\end{abstract}

Keywords: Peace engineering, humanity, science, engineering, policy

\section{Introduction}

Engineer Aarne Vesilind and Robert Textor [1] have come up with the term "Peace Engineering" as a label for ideals such as global environmental management, sustainable 
development, and seeking greater economic justice. The Colorado School of Mines [2] has created a program in "Humanitarian Engineering," which is devoted to research and design intended to improve the well-being of poor and marginalized communities around the world. Several other colleges and universities, including Dartmouth [3] and Ohio State [4], also have Humanitarian Engineering programs. Stanford University [5] introduces a student-led course in learning sustainable design through service. This program's goals are to (a) develop students' iterative design skills, project management and partnership-building abilities, sustainability awareness, cultural sensitivity, empathy, and desire to use technical skills to promote peace and human development, (b) help developing communities ensure individuals' human rights via sustainable, culturally appropriate, technology-based solutions, and (c) increase Stanford University's stewardship of global sustainability. At Drexel University [6], a graduate level program in peace engineering is dedicated to preventing and reducing violent conflict through education and research that integrates innovative technologies, approaches, and policies with the studies and practices of peace builders. These programs serve an important niche in providing engineers with proper training to understand the global dimensions of the issues that impact peace in the world today.

The fabric that makes up nations in this era of human history has significantly changed from what it used to be. Societies that are extremely homogeneous in terms of their human composition are very few. The glue that keeps societies peaceful is much more than absence of conflict or lack of tension. Aspirations for a better life and brighter future are two important factors that individuals in various societies work hard to achieve. A move toward achieving these goals results in a thriving society that is less likely to experience conflict. Peace is the common denominator needed for any society to flourish. Peace does not last without the continuous commitment to avoid war. Peace engineering is an endeavor to help the world achieve prosperity, sustainability, and social equity through innovation, entrepreneurship, transparency, community engagement, and cultural and historical understanding.

Students seeking a study of peace engineering need a better understanding of the type of problems facing the world today. These are multi-faceted problems with widely felt impacts. Many of these problems, such as pollution, contamination, extreme climate events, natural disasters, compromised air quality, water scarcity and lack of sanitation, food shortages, unavailability of energy supplies, disappearance of rainforest, desertification, etc. are daily fixtures in the news and millions of humans in the world suffer the consequences. When desperation engulfs people, reactions ensue, many of which are irrational. For instance, those fleeing places where living seems unbearable or impossible, risk death in uncalculated pursuit of what they consider as a better place. Massive human migration across borderlines, over vast stretches of deserts, and in unpredictable seas are some examples illustrating the extent of the problem. Those fleeing such conditions have reached the point where they see no hope and the only solution, as they see it, is to escape, even if this results in the loss of their own lives.

While developing countries face certain types of problems, developed countries face a different set of problems. The problems related to the climate, environmental pollution, 
and natural disasters may be common for all countries in the world today but people in developing countries have other types of problems on their mind such as penetration of technology into almost all aspects of life, privacy in general and online in particular, raising one's standard of living, fending against hackers in social and financial dealings, identity theft, hazards related to the increased connectivity of devices to the internet (Internet Of Things, IOT), and loneliness, a recent problem stemming from a decrease in meaningful social interaction and erosion of family.

One can easily see that a society in peace with itself, its neighbors, and the world around it can only be achieved with proper diagnosis of the problems causing a state of distress. Due to the diverse nature of problems, students that wish to study peace engineering must be exposed to interdisciplinary and cross-disciplinary courses that amplify the value of recognizing the multidimensional aspect of the problems. Students need training in STEM areas (Science, Technology, Engineering \& Math), economics, politics and policy making, management, entrepreneurship, cultural awareness, and globalization. An exposure to all, or at least a few, of the above fields could prepare individuals to think unconventionally and non-traditionally to solve problems that cannot be solved with old ways of thinking.

This paper details the elements that make up a program in peace engineering at Union College. It is a minor that is open to both engineering and non-engineering students. This minor is housed within a major college-wide program called Environmental Science, Policy, and Engineering (ESPE). The peace engineering minor is structured to give students exposure to a wide variety of science, engineering, and policy courses that help in developing a deep understanding of the complexities in human dealings which, if not resolved peacefully, could ultimately flare into violent conflicts.

\section{Present Day Examples}

There is no shortage of examples of wars and conflicts almost everywhere in the world due to, mainly, poverty and absence of development. An array of factors can contribute to pushing humans to hopelessness and despair. In many, if not all, of these places peace engineering is badly needed to restore hope in a better tomorrow. People need incentive to stay put and to believe a positive change will happen. It is a mindset that humans must attain to have the motivation and the drive to do the job that needs to be done. Those with the proper background and training in how to implement peace engineering are capable of developing a global view of the sources of conflict and devise a plan of action. This is usually a lacking starting point without which nothing will change. In the following, two examples from two different places in the world show how peace engineering can play a positive role in eliminating the sources of conflict and in implementing a plan to deal with the root causes that created the conflict in the first place.

\subsection{The War in Syria}

Trying to dissect the raging war in Syria in a few lines of text will be extremely naïve. This war encompasses an enormous entanglement of political, economic, religious, cultural, historical, and societal aspects [7]. In addition, regional and global powers that 
have something to gain or lose in this part of the world became deeply involved, which added fuel to the fire. For many decades before the eruption of this war, there was relative peace. It was uneasy peace but it maintained a state of no war where people were busy making a living and sustaining a hope for a better tomorrow. Prior to the war, several years of less-than-normal rainfall that created drought conditions [8], coupled with reduced water revenue due to the construction of dams in neighboring countries on rivers supplying Syria with water resulted in a decrease in agriculture activities that kept millions productive and employed. Massive internal migration of population followed. Urban centers became so overcrowded with masses that overwhelmed facilities and sparked friction. Instead of cooperating with each other to solve common problems, people were occupied with thoughts of how to get rid of those who are different and do not share similar views. This war has burned all, caused untold destruction, inflicted serious damage to all warring factions, reduced entire communities to essentially dust and ashes, and the country has lost almost half of its population due to migration to other countries. Talking about how this war could have been avoided is a luxury that no one can afford. The sensible talk now should be about how to end the war and start the effort of rebuilding. To put things in perspective, for rebuilding to be successful, the skills of individuals with training in peace engineering, as detailed above, will be necessary. Eliminating or at least reducing the sources of conflict between people is always the first step toward finding peace. The second step is to give people a reliable way to make a living. Economic prosperity helps in maintaining peace as people become more likely to sustain this peace.

\subsection{The Southern Border of the United States}

The southern border of the United States has been a source of heated political debate for many decades. The problem arises from the migration of tens of thousands of people from Mexico, Central America [9], and South America. The factors that push these migrants out of their homeland are numerous: political unrest, corruption, economic instability, gang violence, drugs, domestic abuse, and lack of opportunity and development. Although a large-scale war cannot be found in any of the countries people are trying to flee, it is the low level continuous unrest and fear of unpredictable future that are taking toll on people and pushing them into seeking what they deem as a better alternative in the United States. Legal migration to the USA requires stressful procedures that, if successful, can take years. Those seeking a better life in the USA know it and this adds to their desperation. To ameliorate the living conditions of would-be migrants, and to keep them away from the thought of leaving their home countries in pursuit of a new life, the USA has been engaging many countries south of the border, especially in Central America, through programs and initiatives designed to engineer peace and to give hope.

Faced with mounting hardship, these efforts are too little to convince thousands of people to stay put and fight for a better tomorrow. Despite the financial aid several countries in Central America receive from the USA, this money and the programs initiated do not provide people with a sufficient reason to believe in a better tomorrow. People have natural tendency to take the path of least resistance and migration, even illegal one, to the USA is their way of getting out of a desperate situation. Peace engineering again seems to be the way forward where understanding the real reasons of the persistence of the drug trade and gang violence is the first step in fighting these activities. This fight has been 
going on, unsuccessfully, for decades and there seems to be no end in sight for these brutal conflicts. Implementing peace engineering, on the other hand, provides effective solutions through the initiation of massive projects to pull thousands out of poverty and make them believe in a better tomorrow.

\section{The Environmental Science, Policy, and Engineering (ESPE) Program}

The Environmental Science, Policy, and Engineering (ESPE) program at Union College is focused on students with an interest in the science and policy behind the myriad environmental problems that face the world, the political policy mechanisms that may provide solutions to these issues, and the interface between the environment and the human condition.

Students in the ESPE program choose either a BS degree in Environmental Science or a BA degree in Environmental Policy. The BS degree emphasizes the biological, chemical, and geological sciences, as well as physics and engineering, while the BA degree emphasizes the social sciences and humanities. A common set of core courses links the two programs. All students take a common introductory course, a core of 8-11 required courses, and 4-6 courses that define an area of concentration. During their senior year, students typically complete two terms of independent research, and participate in a common ESPE senior seminar. The ESPE also offers two minors in environmental engineering and in environmental science and policy. Peace engineering is a third hybrid minor that incorporates elements from science, engineering, and policy.

\section{The Structure of the Peace Engineering Program}

Peace Engineering is an area of study that prepares students to think critically of how to use technical solutions (science and engineering), together with policy, to address societal ills resulting from natural disasters, man-made disasters (wars and conflicts), irresponsible consumption of resources (sustainability issues), public safety (risk assessment), and poverty. This program trains students to pursue practical solutions that proactively promote peace and reduce the potential for disputes in a world plagued with problems that require interdisciplinary way of thinking to solve. Students will have exposure to basic engineering principles in addition to gaining skill in economic, social, environmental, political, ethical, and legal aspects associated with the effort of building enduring peace. The following is a list of the courses that students choose from to complete the requirement for their minor:

\subsection{Required Course}

\section{- Introduction to Environmental Studies}

\subsection{Elective Courses}

Students select either two science courses and three policy/humanities courses, or three science courses and two policy/humanities courses. Courses must be selected from the following lists. No more than two courses may be taken from any one department, and no more than one course may be taken at the 100 level. 


\subsubsection{Science Courses (Biology)}

- Ecology

- Conservation Biology

\subsubsection{Science Courses (Chemistry)}

- Environmental Chemistry

4.2.3. Science Courses (Environmental Science, Policy, and Engineering):

- Food Ecology

- Waste Management and Recycling

- Renewable Energy Systems

- Groundwater Hydrology

- The New Wall of China

- Sustainable Infrastructure

- Environmentally Friendly Buildings

- The Water Paradox

- Construction for Humanity

- Environmental Forensics

\subsubsection{Science Courses (Geology)}

- Environmental Geology

- Natural Disasters

\subsubsection{Policy/Humanities Courses (Anthropology)}

- Environmental Anthropology

\subsubsection{Policy/Humanities Courses (Economics)}

- Environmental and Natural Resource Economics

\subsubsection{Policy/Humanities Courses (History)}

- Big History

- American Environmental History

- Construction for Humanity

- The Nuclear Age

\subsubsection{Policy/Humanities Courses (Philosophy)}

- Environmental Ethics

- Environmental History and Literature

\subsubsection{Policy/Humanities Courses (Political Science)}

- The Environment, Energy, and US Politics

\subsubsection{Policy/Humanities Courses (Sociology)}


- Sociology of Disaster

- Environmental Policy and Resource Management

- Public Health Care Policy and Society

- Environmental Services and Policy

\subsubsection{Terms Abroad (research projects involving environmental topics)}

- Argentina Mini-Term (Focus: Latin America \& Caribbean studies)

- Egypt Mini-Term (Focus: culture \& environmental studies, engineering)

- New Zealand Mini-Term (Focus: engineering, environmental studies, economics)

\section{Peace Engineering in a Nutshell}

Peace engineering is not just a course, or a curriculum. It is not just a minor or a major. It is an integrated way of thinking to address all, or as many as possible, of the factors that undermine peace. It is the appreciation that complex multi-dimensional problems require imaginative and unconventional solutions. It is a comprehension that simplistic solutions to multi-faceted problems are unlikely to produce the desired results. It is ultimately the realization that tremendous work and effort are needed to meet human needs and aspirations. Absent of the above framework, there is little or no chance to engineer peace and avoid conflict.

\section{Students Take Away}

At the completion of the requirements of the peace engineering program described in the above students should be able to:

1. Develop an appreciation of the factors that could lead to conflict and war, and realize that these factors vary by place and time.

2. Develop a perspective of the effect of environmental, social, economical, political, religious, and societal problems in sparking conflicts and heightening their intensity.

3. Devise plans that deal with, and remedy, the ills that deepen conflicts. These plans should focus on restoring peace and dispatching a ray of hope for a better tomorrow.

4. Appreciate that peace engineering is a continuous endeavor of humanity, and that communities need constant supply of dedication and commitment to prosper and thrive.

5. Understand that peace engineering is possible and doable but it requires hard work and perseverance.

\section{Assessment of learning}

Assessment of student learning in this program involved several tools as detailed below: 
1. Almost all the courses students take in this program require extensive class discussion of contemporary as well as historical issues. This discussion is usually based on assigned reading materials that prepare the students for class discussion. Students earn participation points for this component in a given course.

2. Students were assigned different places of war or conflict in the world and were asked to write papers to dissect the sources of conflict. Students were also asked to draft a peace engineering plan, detail the elements of such a plan, and describe how it will create the desired goal of replacing dispute with hope and optimism. Students' papers were assessed where they received a credit for their work.

3. Students were also required to write and present a detailed term paper on an actual conflict of their choice somewhere in the world. This was a research-based paper where an in-depth analysis was expected and a comprehensive proposal of peace engineering was the paper's final goal. Students were heavily invested in studying their selected cases and this was evident in their class oral presentation. Students earned credits for both of their paper and the oral presentation.

4. For a given conflict somewhere in the world, a stakeholder meeting was held where students were given certain roles to play to enrich the classroom discussion. Following a spirited back and forth dissection of the sources of conflict, it was evident that peace engineering was the only way forward. The elements of such a plan and they method of applying it was the next subject of debate. Although there were many moments of heated exchanges, the spirit of respect was prevalent among all participants. Students earned points for their participation in this stakeholder meeting.

5. In addition to all of the above assessment tools, the courses in this program included midterm and final exams.

\section{Evaluation of student performance}

Most of the courses in the peace engineering program place significant weight on student engagement. Instructors are aware of the fact that those who are invested in the subject matter of this minor are eager to share their ideas of how to apply the principles of peace engineering. Courses in this program require students to choose a place somewhere in the world where peace is lacking due to whatever reasons or causes, and are asked to frame a path toward engineering peace in that location. Drafted plans are reported in a paper and are presented to the class for discussion. The conceived plans are sometimes too optimistic or ambitious, or they may require a very long time horizon, or they are thought to do miracles in a short period of time. Students were not restricted in any way, and were indeed encouraged, to develop such plans as long as they can justify and rationalize their proposed actions and illustrate ways to measure progress along the way. Students were given credit for their devised plans based on creativity as demonstrated by the depth of their understanding of the factors that created the problems in the first place and the proposed solutions that will be deployed to address such problems. 


\section{Conclusions}

This paper detailed a program in peace engineering. It is an approach based on developing a deep comprehension of the sources of conflict and war in order to develop a plan for peace and hope. Distress and despair push humans over the edge where irrational acts are committed without much thinking of the consequences. Peace engineering is an attempt to infuse faith in a brighter future through hard work and perseverance. Peace engineering is a tool to get humans to be motivated and excited to implement the elements of a well-detailed plan to address multi-faceted problems. Proper applications of a well-designed plan will almost guarantee the reduction of tension and conflict.

\section{Bibliography}

[1] Harris, C.E., Pritchard, M.S., and Rabins, M.J., James, R., Englehardt, E. (2018). "Engineering Ethics: Concepts \& Cases," 6th Edition, Wadsworth, CENGAGE Learning.

[2] humanitarian.mines.edu.

[3] www.dhedartmouth.org.

[4] osuhe.engineering.osu.edu.

[5] Vesilind, P.A., and Bowen, W.R. (2013). "Peace Engineering: When Personal Values and Engineering Careers Converge," 2nd Edition, Lakeshore Press.

[6] drexel.edu/engineering/academics/areas-of-study-programs/peace-engineering.

[7] Kanthan, C. (2018). "Deconstructing the Syrian War," Kanthan Publishing, CA.

[8] www.npr.org/2013/09/08/220438728/how-could-a-drought-spark-a-civil-war.

[9] Martinez, O. (2017). “A History of Violence: Living and Dying in Central America,” Reprint Edition, Verso Publishers. 